\title{
Photogrammetric and Photometric Investigation of a Smoke Plume Viewed from Space
}

\author{
DaRryi Randerson \\ Air Resources Laboralory, U. S. Department of Commerce, Las Vegas, Nev. \\ and Joe G. Garcia and Victor S. Whitehead \\ Manned Spacecraft Center, NASA, Housion, Tex. \\ (Manuscript received 12 February 1971, in revised form 6 July 1971)
}

\begin{abstract}
Detailed analyses of an Apollo 6 stereographic photograph of a smoke plume which originated in southern Arizona and crossed over into Mexico are presented to illustrate how high-resolution photography can aid meteorologists in evaluating specific air pollution events. Photogrammetric analysis of the visible smoke plume revealed the plume was $8.06 \mathrm{mi}$ long and attained a maximum width of $4000 \mathrm{ft}, 3.0 \mathrm{mi}$ from the 570 -ft chimney emitting the effluent. Stereometric analysis showed that the visible top of the plume rose nearly $2400 \mathrm{ft}$ above stack top, attaining $90 \%$ of this total rise $1.75 \mathrm{mi}$ downwind from the source. Photometric analysis of the plume revealed a field of plume optical density that portrayed leptokurtic and bimodal distributions rather than a true Gaussian distribution.

A horizontal eddy diffusivity of about $6.5 \times 10^{5} \mathrm{~cm}^{2} \mathrm{sec}^{-1}$ and a vertical eddy diffusivity of $2.3 \times 10^{5} \mathrm{~cm}^{2}$ $\mathrm{sec}^{-1}$ were determined from the plume dimensions. Neutron activation analysis of plume samples revealed the elemental composition of the smoke to be copper, arsenic, selenium, indium, antimony, with trace amounts of vanadium and scandium.
\end{abstract}

\section{Introduction}

Recently, Whitehead et al. (1969) showed that cloud photographs taken during the Apollo 6 mission offered significant meteorological information because of their excellent detail and their adaptability to relative height contouring by sterographic photogrammetry. During the Apollo 6 mission 370 color pictures were acquired, 334 of which contained clouds. A single series of these photographs contained a smoke plume. A detailed analysis of these pictures is presented here as an example of how photography of this type may aid in meteorological analysis of specific air pollution incidents. An earlier analysis of such plumes, utilizing earth satellite photographs, was undertaken by Randerson (1968) who demonstrated that satellite photography could be utilized to study the large-scale transport of atmospheric pollutants.

The unmanned Apollo 6 mission was launched from Kennedy Space Center at 1200:01 GMT 4 April 1968. On the third and final orbit the spacecraft achieved an apogee of 22,224 km at 1828:58 and terminated with a landing in the central Pacific Ocean at 2158:45. A secondary objective of the mission was photographic coverage of certain areas using a J. A. Maurer, Model 220G, 70-mm sequence camera mounted inside the spacecraft window. The lens was a Kodak Ektar $f / 2.8$ with a focal length of $76 \mathrm{~mm}$. Prior to flight, the camera aperture was adjusted to $f / 5.6$, and the exposure time was set at 1/500 sec. Exposures were made at 8.64-sec intervals. High-resolution 70-mm Kodak Ektachrome aerial (SO 121) film was used with a Wratten $2 E$ filter.

Almost all the photographs were near-vertical views taken while the spacecraft was in an elliptical orbit with an apogee of $306 \mathrm{~km}$ and a perigee of $184 \mathrm{~km}$. The scale of the imagery ranged from $1: 2,423,000$ to $1: 4,022,000$, and the ground swath coverage varied between 139 and $230 \mathrm{~km}$. Estimated ground resolution was between 23 and $46 \mathrm{~m}$ while the vertical resolution was $100 \mathrm{~m}$. The forward overlap between successive frames was from 54-72\%, making the photographs excellent for stereographic analysis.

The photograph shown in Fig. 1 was taken on 4 April 1968 at 1508 GMT (about 0751 local solar time) from an altitude of $217 \mathrm{~km}$ over southern Arizona. Fig. 1 represents an enlargement of only one picture of a stereographic pair which are not presented to conserve space. In this figure notice the well-defined smoke plume extending from a source in southern Arizona. This plume was emitted from a 570-ft stack of the Phelps-Dodge copper smelter situated $4000 \mathrm{ft}$ MSL near Douglas, Ariz. This picture has been studied to determine what information can be derived concerning the smoke plume in the hope that investigators involved in studies of 


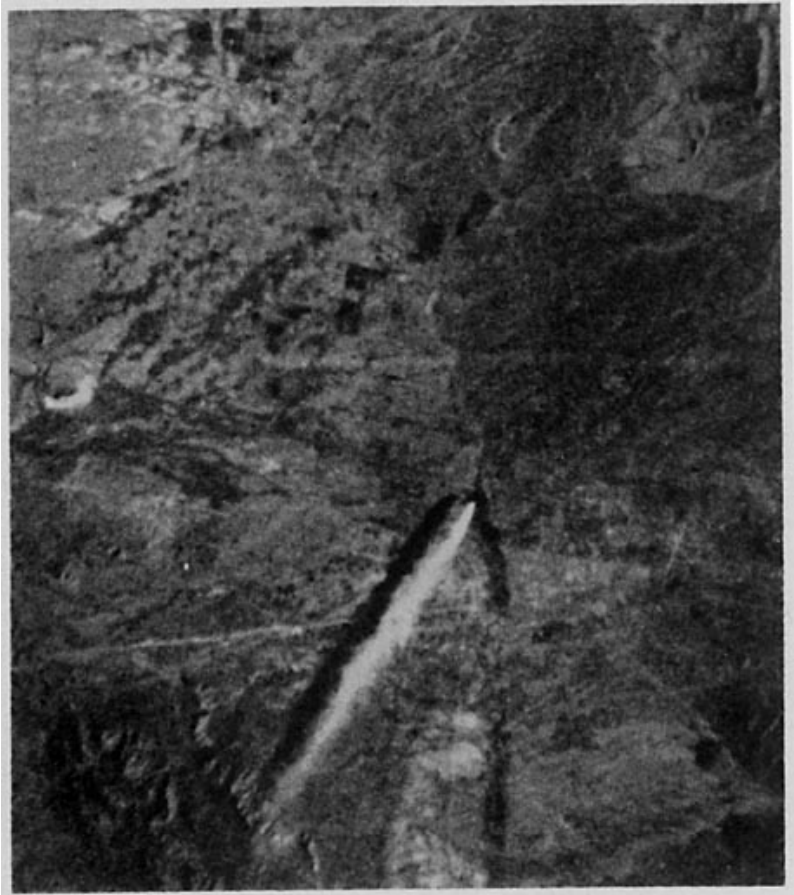

FIc. 1. Enlarged section of an Apollo 6 photograph taken over southern Arizona on 4 April 1968.

the atmospheric transport and diffusion of air pollution can find a useable tool in photography of this sort. Both stereoscopic determination of plume height above terrain and micro-isodensitometric contouring and profiling of the plume have been performed and related to the local meteorological conditions.

\section{Photogrammetric analysis}

The primary purpose in performing a stereographic analysis of the smoke plume was to determine variations in the relative vertical dimensions along the $8.06 \mathrm{mi}$ length of the plume. The map presented in Fig. 2 shows the location of the plume with respect to Douglas and as it extended into Mexico. The height of the plume top above the terrain was determined by applying fundamental concepts of photogrammetry and by utilizing local topographical charts.

The stereoscopic analysis of the smoke plume is considered to be a special application of the more general principles of photogrammetry, which in turn utilizes some of the principles of projective geometry. Since this study is treated as a special problem, certain assumptions can be made and considered valid. First, it is assumed that Apollo 6 earth orbital photography was vertical (a separate NASA in-house study has shown that, at least over the United States, the spacecraft experienced a long-period oscillation, but the camera axis remained plumb to $\pm 2^{\circ}$ from the vertical). By making this assumption, one can relate a vertical photograph to a plan view of the same area.
Differential heights of two or more objects appearing on two overlapping vertical photographs can be determined by measuring their parallax difference. In this specific study the parallax difference between specific points on the smoke plume was measured by graphical methods, as described in the following paragraphs.

Fig. 3 portrays the basic geometry involved in the photogrammetric determination of the varying height of the smoke plume pictured in Fig. 1. In this case the stereographic pair are assumed to be truly vertical, of equal focal length, and that they are images of the same object but exposed from different camera stations $A$ and $A^{\prime}$ (time interval $6 \mathrm{sec}$ ). The distance between the two photographs $\mathrm{A}, \mathrm{A}^{\prime}$ can be determined precisely from the spacecraft ephemeris as can the altitude $H$ above a predetermined horizontal reference plane. In this case an object 0 , the point of the chimney where the plume is originating, has a known elevation $h+h^{\prime}$ above the reference plane. The top of the smokestack images at point $o$ on the first exposure and at $o^{\prime}$ on the second exposure. Since absolute vertical photography is assumed, points $\mathrm{b}$ and $\mathrm{b}^{\prime}$ are both the principal points and nadir points of the photographs. Not shown in Fig. 3 are the conjugate principal points $c$ and $c^{\prime}$ where $c$ represents the principal point of the second photograph identified on the first photograph, and conversely for $\mathrm{c}^{\prime}$.

In each photograph an $x$ axis can be constructed parallel to the spacecraft flight path, or to $\mathrm{AA}^{\prime}$, as well as a $y$ axis perpendicular to the $x$ axis and passing through $\mathrm{b}$ or $\mathrm{b}^{\prime}$. The distances $\mathrm{ob}$ and $\mathrm{o}^{\prime} \mathrm{b}^{\prime}$ are parallel to the $x$ axis. This geometry is illustrated graphically in Fig. 4 , which is composed of triangle Abo for the first photograph and $A b^{\prime}$ for the second photograph. The algebraic difference between $x$ and $x^{\prime}$ is defined as the stereoscopic parallax $p$ of the smokestack. Utilizing the principals of similar triangles and assuming vertical photography, it can be shown that

$$
p / \mathrm{AA}^{\prime}=f /(H-h),
$$

where $f$ is the focal length of camera lens. Provided the base of the smokestack could be resolved on the imagery, the height of the stack could be determined using the foregoing method and the expressions

$$
\begin{aligned}
& \Delta h=\frac{\Delta p\left(H-h^{\prime}\right)}{p^{\prime}+\Delta p}, \\
& \Delta p=\frac{\Delta h p^{\prime}}{\left(H-h^{\prime}\right)-\Delta h} .
\end{aligned}
$$

In Eq. (1) $\Delta h$ represents the change in the value of $h$ or the height of the stack, $h^{\prime}$ the elevation of the base of the stack above the reference plane, and $p^{\prime}$ the parallax of the base of the stack. Eq. (2) is an expression for calculating the change in parallax occurring between the first and second photographs and represents the 


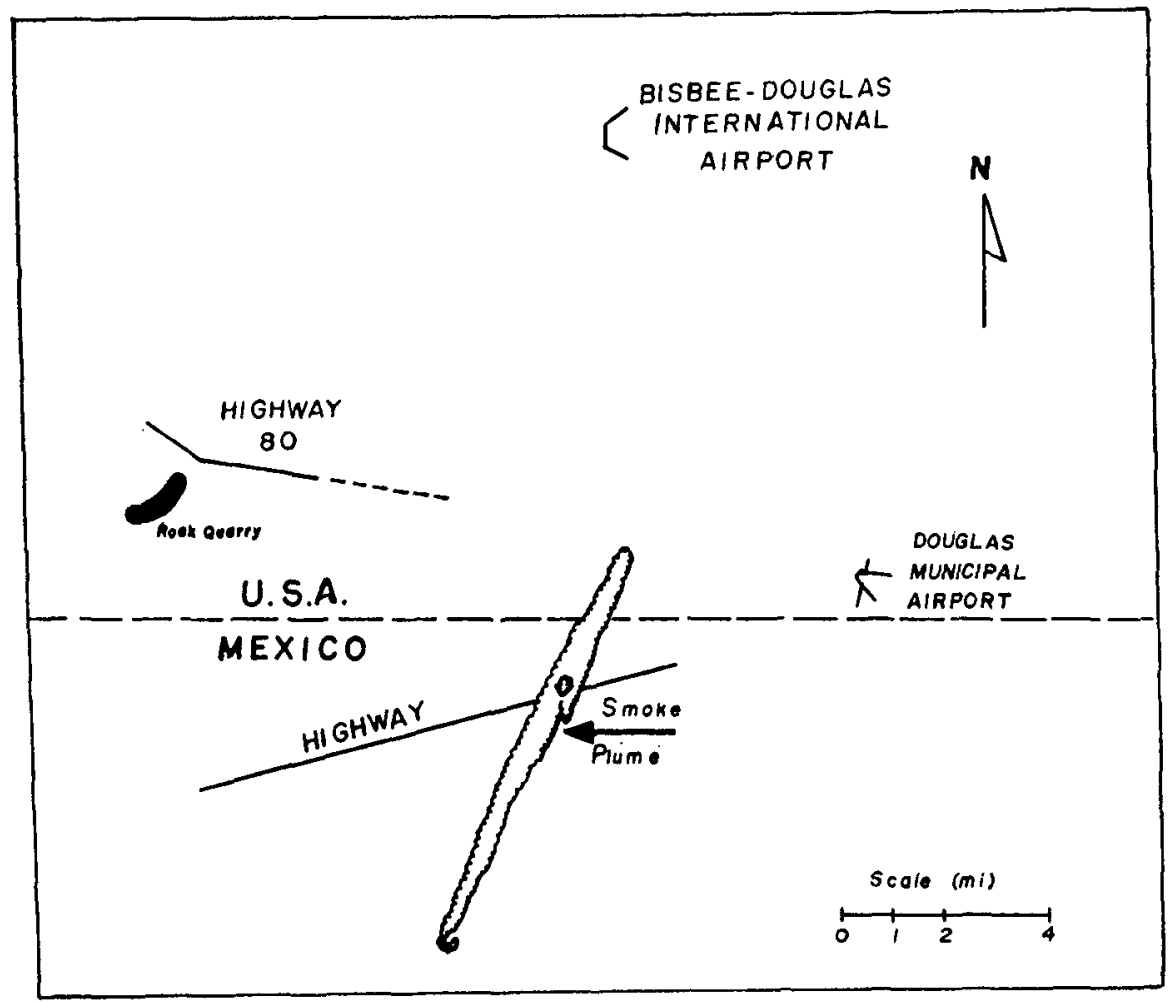

FIG. 2. Landmarks appearing in Fig. 1.

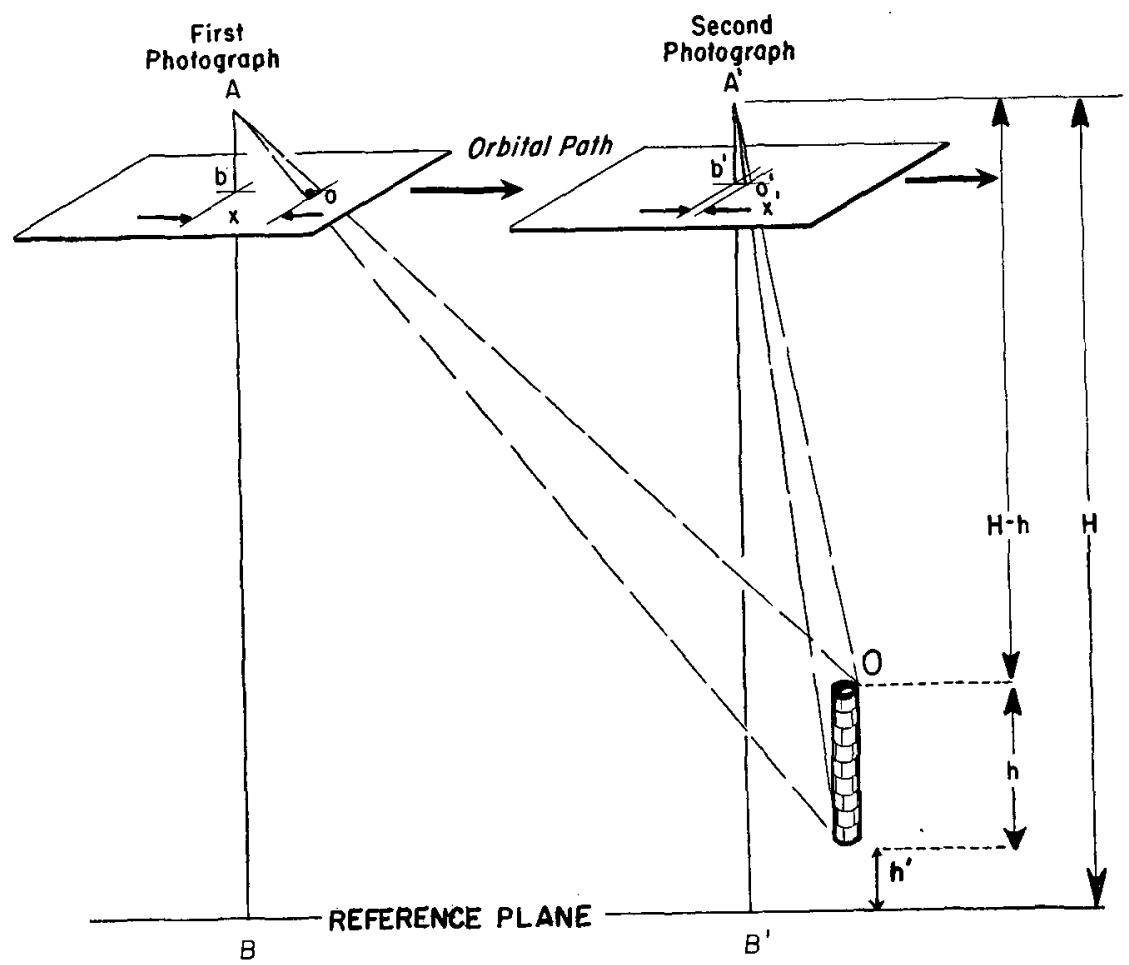

FIG. 3. Basic geometry involved in the photogrammetric determination on the height of the smoke plume. 


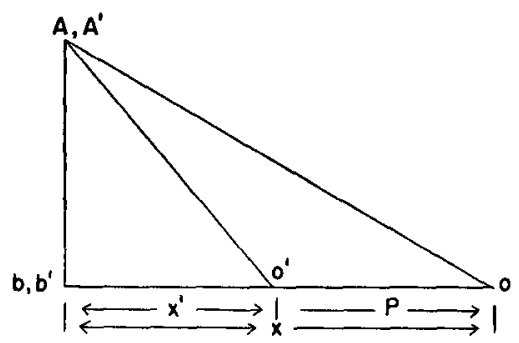

FIG. 4. Geometry of the stereographic pair.

change in elevation between the two parallax points $p$ and $p^{\prime}$.

Based on the previous discussion and Fig. 3, the following steps are taken to measure the parallax difference of the smoke plume in order to determine graphically its elevation above the surrounding terrain:

1) Identify the principal points $b$ and $b^{\prime}$, the conjugate principal points $c$ and $c^{\prime}$, and the image points for which elevations are desired. Mark these points on both photographs of the stereographic pair.

2) Determine the scale of photographic base lengths and from this ascertain the average scale of the photographs.

3) Fasten the photographs so that the two principal points and two conjugate principal points all form a straight line.

4) Draw a straight line on each side of the one just constructed, making the line approximately 1 inch in length and parallel to the line joining the principal points.

5) With a parallax bar determine the distance between an entirely different set of points.

6) Transfer the new parallax bar to the first set of points, holding one end of the bar on one of the principal points. With the other end of the bar establish a point on the line drawn during step 4).

7) The distance between the actual point and the one established during the previous step is known as the parallax difference and represents the difference in elevation between two points.

Since the accuracy of determining elevation differences between points with this technique depends to a great extent on the characteristics of the stereo plates, the calculations will be of very little value if parallax differences are not significant. Consequently, this technique should be used only when the stereo photos are taken from as large a separation as possible (assuming no significant structural changes of the plume) or when the accuracy of the elevations will not have a serious effect on the validity of the study. Care must also be taken in using this technique, since the presence of a moderate amount of tilt $\left(>5^{\circ}\right)$ on the photographs can seriously affect the accuracy of the elevations; in this case however, as mentioned earlier, the Apollo 6 photography was near-vertical. Finally it is also worth noting that while elevation magnitudes can be seriously in error, the fact that heights determined in this case were centralized within a small area of the photographic format means that differences in elevation will not be seriously affected by tilt and should be reasonably accurate.

\section{Photometric analysis}

A photometric analysis of the smoke plume was conducted to obtain a measure of the optical density variations along the total length of the smoke plume. The objective of this analysis was to collect and utilize the available photometric information concerning the differential brightness of the smoke plume, to relate this information to smoke densities within the plume, and to obtain meaningful data concerning the behavior of the smoke plume.

The microphotometric analysis of the cloud image was performed utilizing a four-color isodensitracer and a Joyce-Loebl Microdensitometer. This instrument, as is the case with most scanning equipment, was designed primarily for making quantitative micro-detail measurements of most types of photographic images. Basically, this process is accomplished by reimaging the sample photograph onto a photosensitive cathode so that the microdensitometer can then "read" the logarithm of the folding of the brightness of numerous points on the sample and convert these measurements into units of optical density.

As illustrated schematically in Fig. 5, the operation of the microdensitometer is based on a double-beam light system in which a measuring beam $\mathrm{L}$ and a reference beam $L_{1}$ originate from a single light source $A$. Two right-angle prisms direct the beams $\mathrm{L}$ and $\mathrm{L}_{1}$ toward the center of the instrument. The measuring beam passes through the primary aperture which controls the size and shape of the effective light spot shining on a condenser. Within the condenser a focusing control concentrates the measuring beam of light on the surface of the image. Fig. 5 reveals that the measuring beam next passes through an objective lens, fitted directly above the image specimen, which controls the focus of the image on the final aperture. Behind this aperture a lens focuses the light beam onto the cathode area of the photomultiplier. Simultaneously, the reference beam passes through a density wedge which controls the baseline wedge. The baseline wedge is adjusted to balance the recording pen between the minimum and maximum density levels based on the specific density range controlling the amplitude of the recording. The beam then passes through a prism system which focuses the beam toward a rotating shutter disc.

By the time the reference beam and the measuring beam arrive at the rotating shutter they are very nearly parallel. The shutter disc is carefully synchronized so that during half the period the measuring beam is exposed to the cathode while the reference beam is exposed 


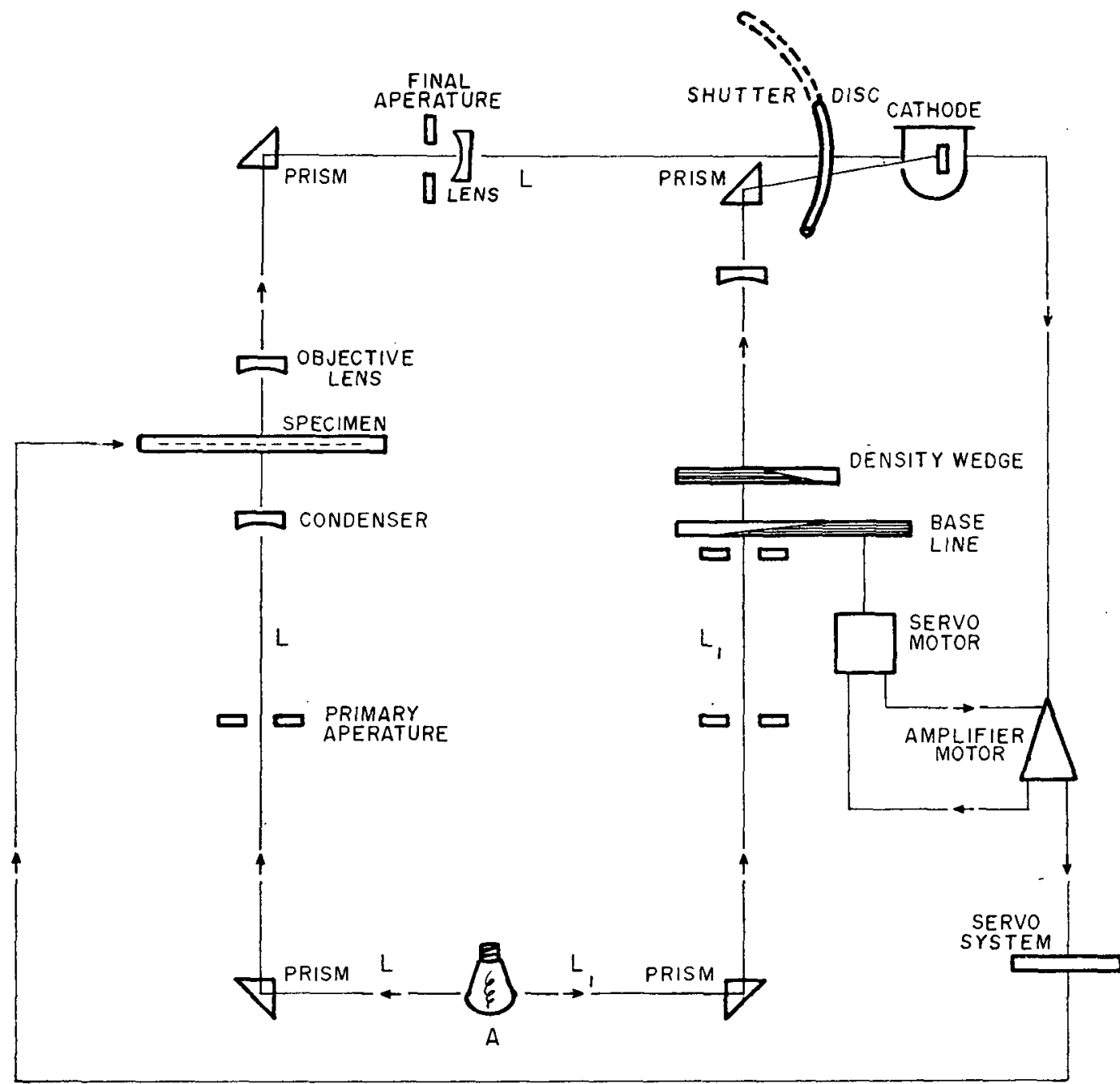

FIG. 5. Schematic diagram of the microdensitometer.

during the other half. Both beams are adjusted so that they impinge on the same area of the photosensitive cathode.

The signal produced by the photomultiplier due to a difference in the light intensity is amplified, and, through a servo motor, drives an optical attenuator in a manner which will reduce this difference to zero. The difference in light intensity is kept continuously at a null position, thus making the optical attenuator record the density at any spot on the image specimen. The image specimen and the recording table are also driven by a servo system so as to record the change in densities sensed by the photomultiplier cathode system.

\section{Plume environment and morphology}

During the period 1-3 April 1968, an analysis of the large-scale meteorological features revealed that a midtropospheric cyclone, from the eastern Pacific Ocean, passed over the southwestern United States. By the evening of 3 April, this storm system was over south- eastern Colorado and moving steadily northeastward. Consequently, the atmosphere over Arizona was rapidly assuming the characteristics of a continental polar air mass and surface pressure gradients over Arizona were weakening, thereby generating gentle surface winds. With clear skies, light winds, and a dry air mass over the southwestern United States, nocturnal radiational cooling was likely to occur.

The mesoscale meteorological conditions existing during the period of interest could be approximated from available data. Atmospheric soundings for El Paso, Tex., and Tucson, Ariz., were used to aid in documenting the thermal and moisture structure of the atmosphere in the vicinity of Douglas. El Paso is located approximately $185 \mathrm{mi}$ east of Douglas while Tucson is situated $100 \mathrm{mi}$ northwest of Douglas. In the vicinity of Douglas the terrain is rather mountainous so that local meteorological conditions might be quite variable from valley to valley. Consequently, the two measured soundings plotted in Fig. 6 were used only as an indicator of the 
general thermal structure and moisture content of the atmosphere over Douglas. Clearly, the orientation of the smoke plume in Figs. 1 and 2 indicates that the upper portions of the plume were being transported by air flowing from the north-northeast or from about $25^{\circ}$. The limited horizontal distribution of the visible plume also indicates a lack of directional wind shear in the vertical, implying that the air flow throughout the depth of the plume was from the same direction. Also, Fig. 6 indicates that the environmental relative humidity in the vicinity of the smoke plume was roughly $45 \%$ so that it is unlikely that the visible plume consisted of condensed water vapor.

Supplemental surface synoptic data were available from Douglas Municipal Airport situated $4.63 \mathrm{mi}$ from the stack emitting the smoke. At 1200 GMT the reported surface temperature at Douglas was 0C, the sky was clear, visibility was excellent, and the wind was calm.

The soundings in Fig. 6 indicate radiational cooling was occurring over the region so that it is logical to assume that this type of atmospheric cooling was occurring at Douglas during the morning of 4 April. An evaluation of the estimated depth and magnitude of this cooling was obtained from the soundings in Fig. 6. In both measured soundings the temperature inversion associated with this cooling was about $20 \mathrm{mb}$ deep. The light winds observed at El Paso probably acted to reduce the amount of cooling that could have occurred with calm wind conditions. Based on hourly snoptic observations from Douglas and the proximity of Douglas to Tucson, the depth of boundary-layer radiational cooling at Douglas was assumed to be similar to that at Tucson. Above this nocturnal inversion the thermal structure of the atmosphere over Douglas was considered to be very similar to that over both Tucson and El Paso so that the potential temperatures in the upper air layers would be approximately homogeneous. These considerations led to the construction of the solid sounding curve in Fig. 6, representing the proposed thermal structure of the atmosphere over Douglas. Based on this structure, the stack height, and the buoyant plume rise (to be discussed next), the buoyant force of the plume was apparently great enough to break through the nocturnal inversion and enter the neutrally stable air above.

The smoothed photogrammetric analysis of the smoke plume, presented in Fig. 7, yielded some noteworthy information. For example, calculations showed the visible plume to be $8.06 \mathrm{mi}$ in length, with a width of 4000 $\mathrm{ft}$ at a distance of $3 \mathrm{mi}$ from the source. A maximum altitude of nearly $3000 \mathrm{ft}$ above the ground was achieved $3.45 \mathrm{mi}$ from the source. The cross section in Fig. 7 also reveals that the plume rose nearly $2400 \mathrm{ft}$ above stack top, attaining $90 \%$ of this height at a downwind distance of $1.75 \mathrm{mi}$ from the source. Within a distance of only 10 stack heights $80 \%$ of the total plume rise was achieved.

Fig. 1 reveals that the visible plume remains rather

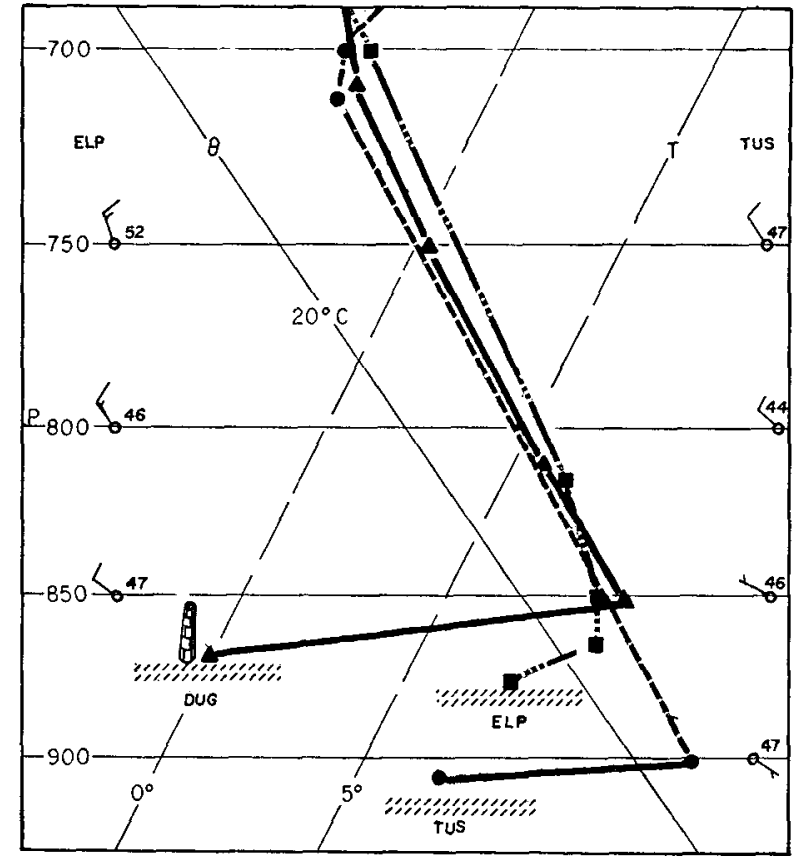

Fic. 6. A skew $T, \log P$ diagram containing the observed (1200 GMT 4 April) soundings for Tucson, Ariz. (TUS) and El Paso, Tex. (ELP), and the simulated sounding for Douglas, Ariz. Numbers plotted to right of wind barbs represent relative humidity.

compact over its entire length implying that the plume was not being vigorously mixed by convective eddies or by mechanically generated turbulence. In other words, the shape of the plume suggests that it was being advected, relatively intact, by a laminar-type air flow regime.

Another important consequence of Fig. 1 is that it documents a case of international pollution. Thus, from Fig. 2, it can be seen that at picture time nearly $85 \%$ of the visible plume was over Mexico.

Stereoscopic elevations of the top of the visible plume were determined at points $A$ through $E$ shown in the cross section in Fig. 7. In this figure notice how the visible top of the plume appears to rise to near point $\mathrm{C}$ and then experiences a drop in altitude from point $\mathrm{C}$ to points $\mathrm{D}$ and $\mathrm{E}$, the most significant decrease in elevation occurring between points $C$ and $D$. No conclusive explanation can be given for this sudden height change; however, the photometric analysis in Fig. 8 shows that a small-scale eddy might have been mixing the air near points $C$ and $D$, causing the apparent height change. The continued subsidence between points $D$ and $E$ could have been the result of a decrease in the visible portions of the cloud below the threshold of sensitivity of the microdensitometer.

Photometric analysis of Fig. 1 gave the transmissivity contours shown in Figs. 8 and 9 which portray the optical density field associated with the visible plume, an outline of the shadow cast by the plume, and the 


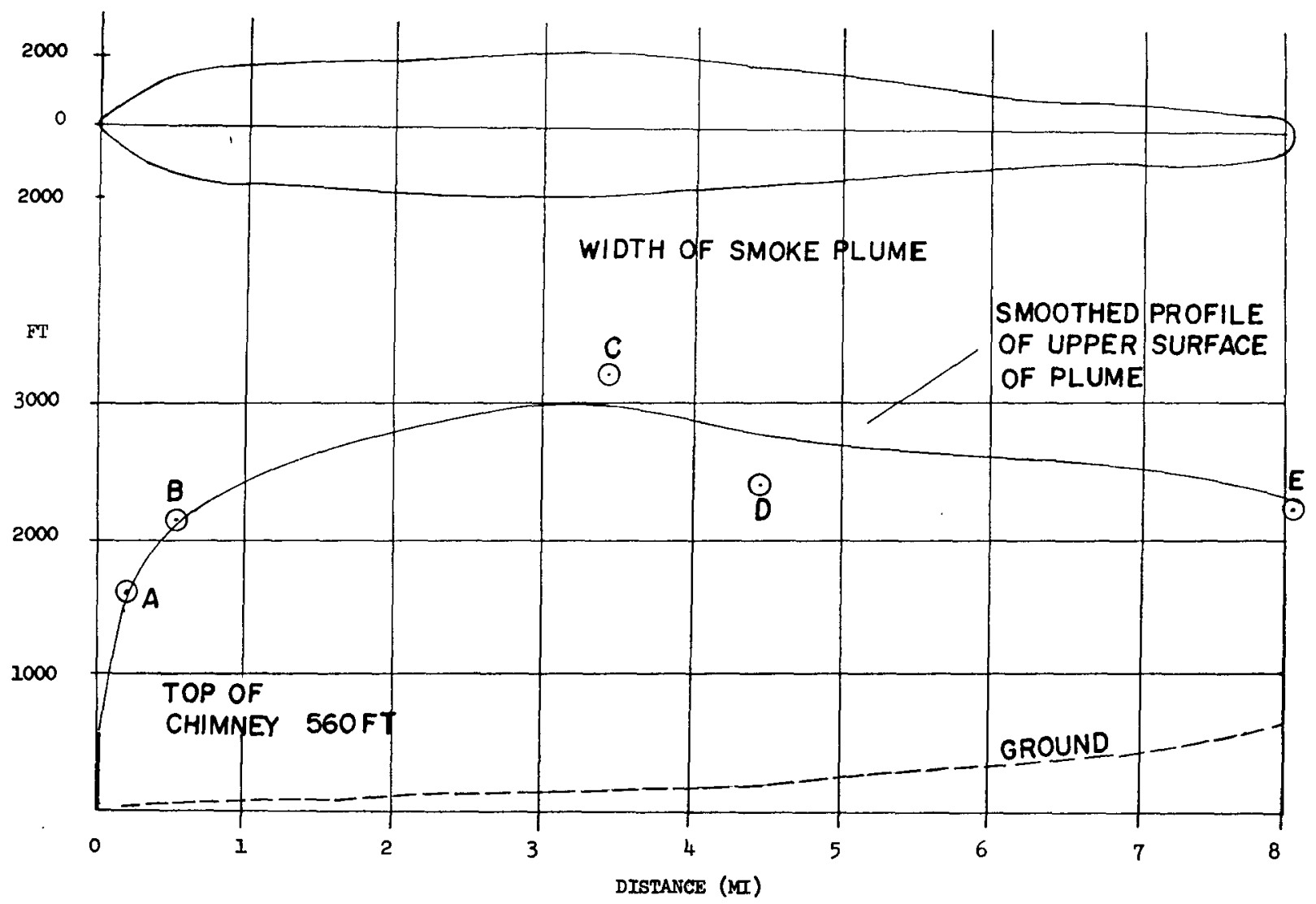

FIG. 7. Cross-sectional and plan view of the visible plume top.

optical density profiles utilized to derive Fig. 8. In Fig. 8 the contours portraying the optical density field represent the percentage of light transmitted through the photograph in Fig. 1. Contour 1 represents a 75\% transmissivity, contour 2 a $50 \%$ transmissivity, contour 3 a $25 \%$ transmissivity, and contour 4 a $1 \%$ transmissivity which is close to the threshold sensitivity of detection of the plume by the microdensitometer. Fig. 9 illustrates some of the cross-sectional profiles of optical density taken at various positions along the visible plume axis. In this figure notice that in the two profiles nearest the source the optical density distributions are leptokurtic and that in profiles $3,4,5$ and 7 they become bimodal.

Examination of the optical density fields in Figs. 8 and 9 indicates that at approximately 3.0 and $7.5 \mathrm{mi}$ from the stack, two small-scale anomalies appear to be present in the smoke plume. These anomalies apparently resulted from small-scale perturbations, one appearing as a cyclonic swirl near the end of the plume, the other portrayed by a sharp optical density gradient located $3 \mathrm{mi}$ from the source. The longitudinal distance between these two disturbances is approximately $4.5 \mathrm{mi}$ and the estimated wind speed $5 \mathrm{mph}$. Available data are insufficient to offer an explanation for the physical generation of these anomalies.
The most exciting consequence of Figs. 8 and 9 is the possibility of relating the optical density contour field to the concentration field of a visible gas or to the distribution of particulate matter along the cloud top. Provided an empirical expression can be obtained relating the optical characteristics to concentration parameters, aerial photography of large-scale pollution episodes might be an economical means of obtaining some quantitative evaluation of the extent and dynamics of pollution clouds.

Little quantitative information could be assembled to aid in identifying the chemical composition of the smoke plume; however, a special filter paper sampling of this plume was made on 10 July 1970, as part of Project Cold Flow being conducted by the Los Alamos Scientific Laboratory. Knowing that the smelter operated continuously $24 \mathrm{hr}$ per day and assuming that the operational capacity and processing techniques of the copper smelting plant remained the same, these aerometric data should provide a reliable indication of the elemental composition of the smoke plume. Beginning at about $1630 \mathrm{GMT}$, sampling was conducted from an aircraft flying $1500-2000 \mathrm{ft}$ above the ground at a speed of 200 $\mathrm{kt}$. Observations of the plume morphology indicated that diffusion was suppressed, and the smoke plume was 


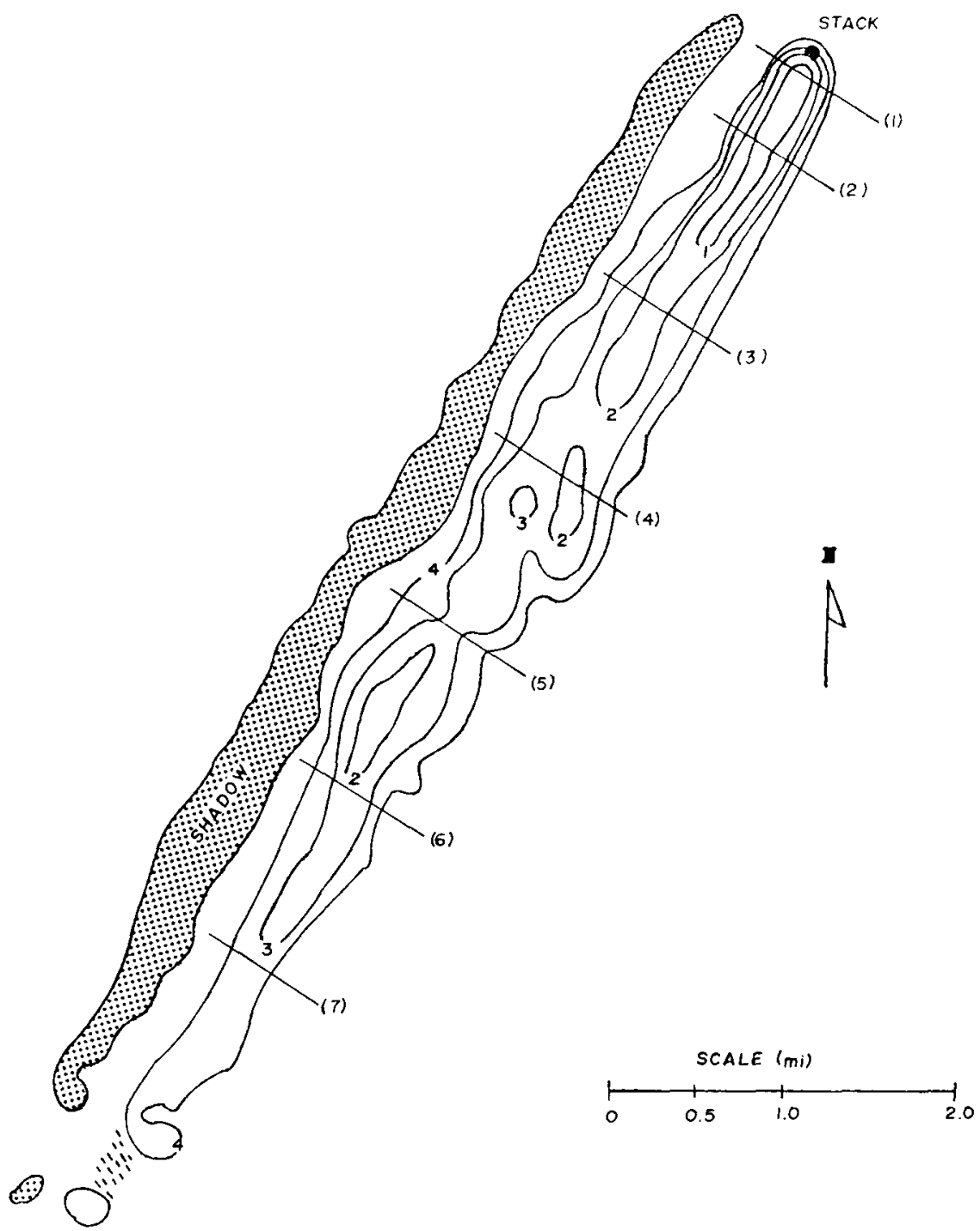

FIG. 8. Photometric analysis. Numbers in parenthesis identify the cross sections appearing in Fig. 9. Contour codes are $1,75 \%$ transmissivity; $2,50 \% ; 3,25 \% ; 4,1 \%$.

visible as far as one could see into Mexico. ${ }^{1}$ Analysis of the filter paper sample by neutron activation permitted identification of some of the constitutents contained in the plume, which, of course, does not necessarily mean that these particular constituents were responsible for the visible plume. Five elements were detected in the plume; namely, copper, arsenic, selenium, indium and antimony. Trace amounts of vanadium and scandium were also present. Copper, arsenic, selenium and indium have been observed in the smoke plumes from two other copper smelting plants in Arizona. ${ }^{1}$ In terms of suspended particulate material, the mass loading of the Douglas sample was $72 \mu \mathrm{g}$ per cubic meter of air.

Techniques of utilizing smoke-plume photographs to obtain quantitative estimates of diffusion were first

\footnotetext{
1 Paul Guthals (private communication).
}

proposed by Richardson (1920) and Roberts (1923), and recently applied by Holland (1953), Bowne (1961), Culkowski (1961), and Högström (1964) to name a few. One basic requirement in utilizing photographs for diffusion estimates is that the plume should be viewed from a height sufficient to give a complete horizontal view of the entire plume; the requirement is obviously satisfied in this case. Consequently, if we assume that the photograph is a reasonable measure of the average plume dimensions, the total density of smoke particles along a line of sight can be determined from

$$
\int_{-\infty}^{\infty} \frac{x}{Q} d z=\frac{\exp \left(-y^{2} / 2 \sigma_{y}{ }^{2}\right)}{2 \pi \sigma_{y} \sigma_{z} \bar{u}} \int_{0}^{\infty} \exp \left(-z^{2} / 2 \sigma_{z}^{2}\right) d z
$$

where $x$ is concentration, $Q$ source strength, $\sigma_{y}$ and $\sigma_{z}$ 


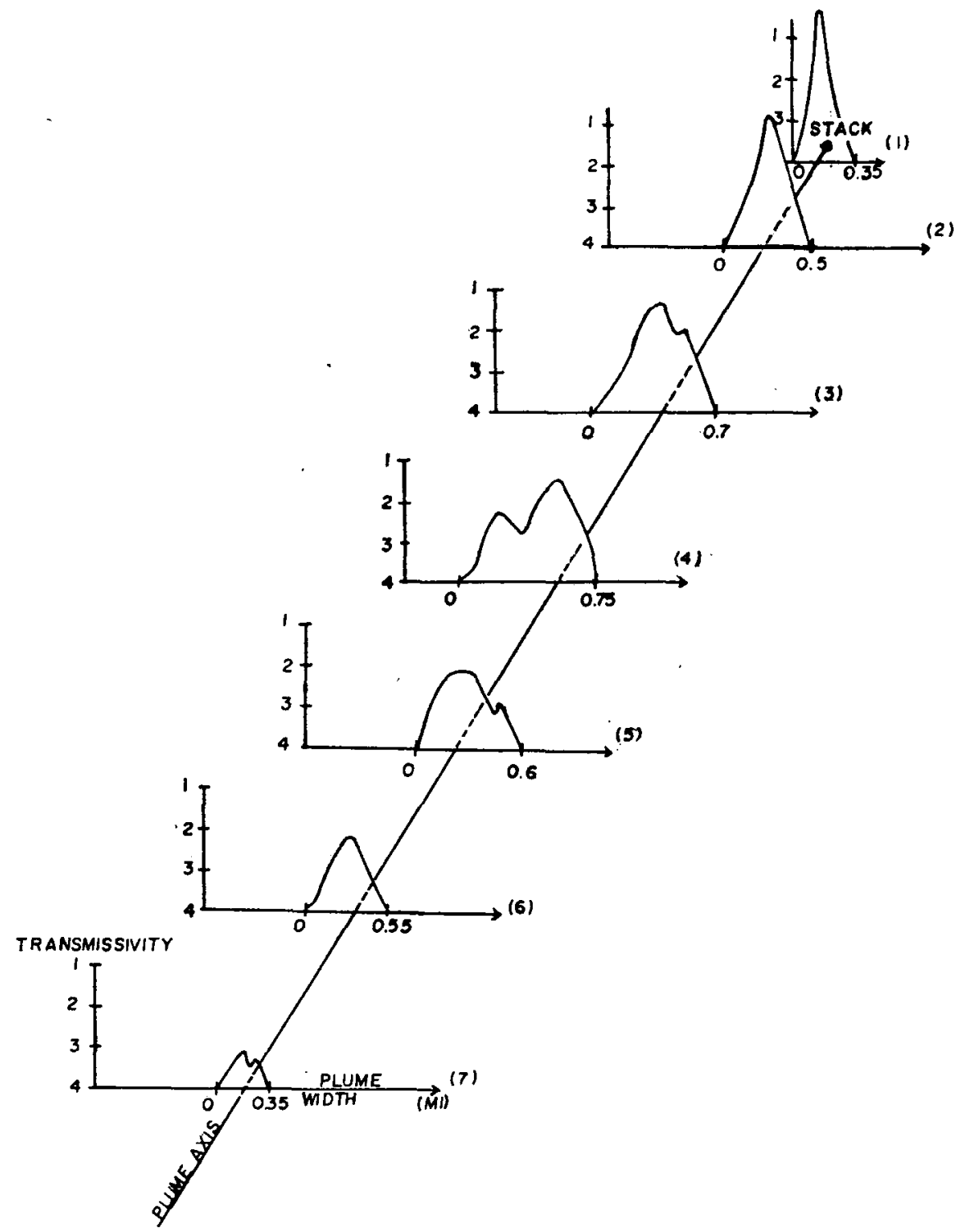

FIG. 9. Optical density distribution along the smoke plume.

the lateral and vertical standard deviation of $x$, and $\bar{u}$ the mean wind speed through depth $d z$. Note that Eq. (3) relates dispersion to a fixed axis so that it can apply only to a mean concentration distribution. Gifford $(1959,1968)$ generalized Eq. (3) to several simple formulas specially adapted to yield diffusion coefficients directly from photographic measurements of average plume dimensions. Of particular interest in this case are the following two equations for evaluating the horizontal eddy diffusivity $K_{y}$ :

$$
\begin{aligned}
& K_{y}=\bar{u} Y_{m}^{2} e^{\frac{1}{3}} /\left(2 X_{t}\right), \\
& K_{y}=\bar{u} Y_{m}{ }^{2} /\left(2 X_{m}\right),
\end{aligned}
$$

where $X_{t}$ is the total plume length, and $X_{m}$ the distance downwind from the source at which the maximum plume width $Y_{m}$ occurs. Assuming $\bar{u}=5 \mathrm{mph}$ and utilizing Figs. 7 and 8 to obtain $X_{t}=8.06 \mathrm{mi}, Y_{m}=0.38 \mathrm{mi}$ and $X_{m}=3.0$ mi, solutions to Eqs. (4) and (5) yield $4.46 \times 10^{5}$ and $8.59 \times 10^{5}$, respectively, after the appropriate conversion of units, or an approximate average value of $6.5 \times 10^{5} \mathrm{~cm}^{2} \mathrm{sec}^{-1}$.

Similar type equations can be employed to obtain estimates of the vertical eddy diffusivity $K_{z}$; here we have

$$
\begin{aligned}
& K_{z}=\bar{u} Z_{m}^{2} /\left(2 X_{m}\right), \\
& K_{z}=\bar{u} Z_{m}^{2} e^{\frac{1}{2}} /\left(2 X_{t}\right),
\end{aligned}
$$

where $Z_{m}$ is the maximum half height of the plume, $(1200 \mathrm{ft})$ at distance $X_{m}$. Solutions to (6) and (7) yield $K_{z}=3.09 \times 10^{5}$ and $1.50 \times 10^{5} \mathrm{~cm}^{2} \mathrm{sec}^{-1}$, or an average 
value of about $2.3 \times 10^{5} \mathrm{~cm}^{2} \mathrm{sec}^{-1}$. These data show, in this microscale case, that

$$
K_{y}=2.8 K_{z},
$$

which implies that, at any given time, the diffusion in the $y$ direction was greater than that in the $z$ direction. Similar anisotropy was obtained by Kao and Wendell (1968) from tetroon data for a time period of about $2 \mathrm{hr}$; however, their calculations indicated that

$$
K_{y}=10 K_{z} .
$$

The difference between Eqs. (8) and (9) is not too surprising since the ratio of $K_{y}$ to $K_{z}$ should vary with vertical stability and with the scale of the turbulence present.

\section{Summary}

Stereographic photography from space has been shown to be a useful means of documenting the threedimensional structure of a smoke plume. For example, in this case study the stereographic photographs not only permitted the plume length of $8.06 \mathrm{mi}$ to be determined, but also permitted an evaluation to be made of variations in the height of the cloud top above ground. Computations showed that the maximum height of the smoke plume was $3000 \mathrm{ft}$ above the ground, yielding a plume rise of about $2400 \mathrm{ft} ; 80 \%$ of the total rise occurred within 10 stack diameters. The maximum width of the visible plume was $4000 \mathrm{ft}, 3.0 \mathrm{mi}$ from the $570-\mathrm{ft}$ chimeny emitting the effluent. Photometric analysis of the plume revealed a field of optical density that portrayed leptokurtic and bimodal distributions rather than a true Gaussian distribution.

Calculations of the eddy diffusivities of the smoke plume yielded values of $6.5 \times 10^{5}$ and $2.3 \times 10^{5} \mathrm{~cm}^{2} \mathrm{sec}^{-1}$ for the horizonal and vertical components, respectively. Based on these numbers, $K_{y}$ was 2.8 times larger than $K_{z}$ in this particular case.

Fig. 1 also documents a case of international pollution. After traveling $1.2 \mathrm{mi}$, the smoke plume entered Mexican airspace with nearly $85 \%$ of the visible plume being in Mexico.

Neutron activation analysis revealed that the plume contained the elements copper, arsenic, selenium, indium, antimony, and trace amounts of vanadium and scandium. Mass loading of the filter paper sample was $72 \mu g$ per cubic meter of air.

High-resolution, stereographic photography from high altitudes offers research meteorologists a new and promising tool. Even without accompanying surface data, certain features of atmospheric structure can be inferred. In addition, the shape, size and height of visible clouds of pollution, viewed on the scale presented here, may offer valuable data for studying mesoscale features of the atmospheric transport and diffusion of pollutants.

Several carefully controlled experiments are needed to determine the accuracies of the height determination of smoke plumes and to correlate the optical density field with observed concentrations of gaseous and particulate material. Also, valuable information on the diminution of solar radiation by pollution might be obtained from relationships between the optical density field and the shadow created by the attenuation of light.

Acknowldgments. Sampling of the smoke plume was conducted under Project Cold Flow by Messrs. Paul Guthals, H. L. Smith, Wm. Sedlaeck, R. A. Easton, David Clinton, and Ted Norris of the Los Alamos Scientific Laboratory (LASL), Group J-11. Activation analysis of the samples was provided by LASL Group P-2 and the aircraft was provided by the 58th WRS, Kirtland AFB, N. M. Mr. H. H. Slater of the Environmental Protection Agency, Office of Air Programs, provided several helpful comments concerning smoke plume morphology.

\section{REFERENCES}

Bowne, N. E., 1961: Some measurements of diffusion parameters from smoke plumes. Bull. Amer. Meteor. Soc., 42, 101-105.

Culkowski, W. M. 1961: Time exposure photography of smoke plumes. USAEC Rept. ORO-359, Weather Bureau, Oak Ridge, Tenn.

Gifford, F. A., 1959: Smoke plumes as quantitative air pollution indices. Intern. J. Air Pollution, 2, 42-50.

-.-, 1968: An outline of theories of diffusion in the lower layer of the atmosphere. Meteorology and Atomic Energy, 1968, Gov't. Printing Office, 65-116.

Högström, U., 1964: An experimental study of atmospheric diffusion. Tellus, 16, 205-251.

Holland, J. Z., 1953: A meteorological survey of the Oak Ridge area: Final report covering the period 1948-1952. USAEC Rept. ORO-99, Weather Bureau, Oak Ridge, Tenn.

Kao, S. D., and L. L. Wendell, 1968: Some characteristics of relative particle dispersion in the atmosphere's boundary layer. Atmos. Environ., 2, 397-407.

Randerson, D., 1968: A study of air pollution sources as viewed by earth satellites. J. Air Pollution Control Assoc., 18, 249-253.

Richardson, L. F., 1920: I. Some measurements of atmospheric turbulence. Phil. Trans. Roy. Soc. London, A221, 1-28.

Roberts, O. F. T., 1923: The theoretical scattering of smoke in a turbulent atmosphere. Proc. Royal Soc. London, A104, 640-654.

Whitehead, V. S., I. D. Browne and Joe G. Garcia, 1969: Cloud height contouring from Apollo 6 photography. Bull. Amer. Meteor. Soc., 50, 522-528. 